\title{
Maternidades grotescas nas narrativas de Angela Carter, Lya Luft e Susan Swan
}

André Pereira Feitosa

Doutor em Literatura Comparada / UFMG

\begin{abstract}
RESUMO
O presente trabalho tem como objetivo o estudo comparativo das obras Noites no circo, de Angela Carter, Exílio, de Lya Luft, e The biggest modern woman of the world, de Susan Swan, enfocando, entre as características do grotesco feminino, a maternidade que se distancia dos modelos considerados normais.
\end{abstract}

\section{PalaVRas-CHAVE}

Grotesco, maternidade, feminismo, alteridade

\section{O MITO DA FAMÍLIA FELIZ}

Tradicionalmente, em sociedades patriarcais, a imagem da mulher virtuosa tem na maternidade uma de suas funções sociais mais relevantes a serem cumpridas. Nas obras Noites no circo, de Angela Carter, Exílio, de Lya Luft, e The biggest modern woman of the world, de Susan Swan, essa concepção idealizada de perfeição, em que ser mãe é concebida como uma característica intrínseca à natureza feminina, é muitas vezes questionada. As obras de Carter, Luft e Swan, cada uma a seu modo, desmistificam os modelos cristalizados de feminilidade utilizando representações grotescas da maternidade.

Susan Swan afirma, em entrevista, que "as mulheres têm tido medo de realmente revelarem suas emoções negativas quanto à maternidade”, o que também engloba "suas frustrações, seus sensos de raiva, seus sensos de falta de poder”. ${ }^{1}$ Mesmo afirmando que sua experiência pessoal como mãe tenha sido emocionalmente gratificante, a autora observa que

\footnotetext{
1 "Women have been frightened to really reveal the darker emotions that have gone with mothering about their frustrations, their sense of anger, their sense of powerlessness." (SWAN. Breaking the maternal silence: no more Good mothers, p. 219, tradução nossa.)
} 
“a maternidade é a profissão menos bem paga, menos reconhecida e mais supersentimentalizada do mundo". ${ }^{2}$ A entrevistadora, Sarah Sheard, também pontua que "nós raramente vemos imagens positivas de mulheres como mães na literatura”. ${ }^{3}$ Geralmente, os arquétipos de mães veiculados na mídia coincidem com o que Swan qualifica de "um modelo aprisionador de feminilidade", ${ }^{4}$ no qual a mãe está “constantemente alegre e preocupada em cuidar das necessidades das outras pessoas da família”. ${ }^{5}$ A autora afirma que, caso a mãe se desvencilhasse desse padrão, correria o risco de ser estigmatizada e considerada egoísta. Esse modelo de mãe, sustentado como perfeito, em que a passividade e a submissão materna perante seus maridos regem a estrutura familiar, também tem sido criticado por várias feministas, como Betty Friedan, Adrienne Rich e Simone de Beauvoir. Friedan chega mesmo a nomear a maternidade e os trabalhos domésticos como um “campo de concentração confortável,"6 e ironiza a condição dessa mãe que se submete a tal confinamento, denominando-a de "heroína dona-de-casa feliz", 7 enfatizando que muitas mulheres sofrem dessa “dolorosa insatisfação”» por pensarem que estão sozinhas nessa condição subalterna.

Luft percebe essa solidão como "um fantasma que assusta mais as mulheres do que os homens”, acrescentando que muitas “ainda são educadas para fazerem par com homem” em uma relação na qual elas representam “a parte mais frágil dessa combinação”. ${ }^{9}$ Esse ideal de união a um homem, tradicionalmente reforçado para as mulheres, pode criar o que a autora considera um dos "temas centrais” a ser questionado em suas obras: “[o] mito da família feliz.” Os modelos tradicionais de família são vistos por Luft como uma "idealização ingênua” e, em suas narrativas, lhe “interessa o lado avesso das coisas”, para que esse

\footnotetext{
2 "Motherhood is the most under-paid, under-acknowledged, and over-sentimentalized job in the world.” (SWAN. Breaking the maternal silence: no more good mothers, p. 212, tradução nossa.)

3 "We rarely see positive images of women as mothers in literature." (SWAN. Breaking the maternal silence: no more good mothers, p. 212, tradução nossa.)

4 “(...) an imprisoning model of femininity.” SWAN. Breaking the maternal silence: no more good mothers, p. 207-221, tradução nossa.)

5 “(...) constantly cheerful and looking after the needs of other people in the family." (SWAN. Breaking the maternal silence: no more good mothers, p. 212, tradução nossa.)

6 “(...) comfortable concentration camp”. (FRIEDAN. The feminine mystique, p. 393, tradução nossa.)

7 “(...) happy housewife heroine”. (FRIEDAN. The feminine mystique, p. 393, tradução nossa.)

8 “(...) aching dissatisfaction (...).” (FRIEDAN. The feminine mystique, p. 79, tradução nossa.)

${ }^{9}$ LUFT. Múltipla escolha, p. 41.
} 
arquétipo seja desmistificado. ${ }^{10}$ Reforçando os argumentos de Luft e de Swan, Carter afirma que:

\begin{abstract}
Se as mulheres se permitem ser consoladas pela falta de acesso aos modos de debate intelectual, culturalmente determinados a elas, pela invocação de grandes deusas hipotéticas, estão simplesmente se vangloriando da própria submissão (uma técnica usada frequentemente pelos homens). Todas as versões míticas das mulheres, do mito da pureza redentora da virgem ao da que cura, da mãe reconciliadora, são bobagens de consolação; e bobagens de consolação me parecem uma definição justa de mito, de qualquer modo. A noção de deusas mãe é tão tola quanto à de deuses pais. Se um retorno aos mitos desses cultos dá satisfação emocional às mulheres, o preço pago para isso é o obscurecimento das reais condições de vida. É para isso que foram inventados, em primeiro lugar. ${ }^{11}$
\end{abstract}

Dessa forma, Carter expõe duas preocupações quanto ao posicionamento da mulher diante desses mitos. Primeiro, a alienação de sua condição subserviente imposta pelas culturas falocêntricas. Segundo, a criação de mitos femininos que reforçam o modelo tradicional de mulher no qual a maternidade é umas das metas a serem seguidas. O perigo encontra-se, segundo a autora, no conforto que tais imagens podem proporcionar às mulheres, remetendo ao efeito do placebo religioso criticado por feministas como Adrienne Rich, Betty Friedan e Simone de Beauvoir.

Várias críticas da atualidade, como Cristina Stevens, concordam com tais questionamentos sobre modelos tradicionais de maternidade. Stevens afirma que "essas formulações patriarcais tiveram - e ainda têm - impacto incalculável na vida de homens e mulheres, e por isto têm merecido a atenção de feministas, sobretudo nas três últimas décadas". ${ }^{12}$ A literatura muitas vezes se espelha em estudos sociológicos, e a complexidade das representações maternas aumenta "à medida que o sentido de maternidade se diversifica, uma vez que à mãe tradicional vem juntar-se a mãe adotiva, a mãe lésbica, o homossexual que materna, a mãe de aluguel, a mãe adolescente, a mãe solteira, a mãe prisioneira, a mãe pobre,

\footnotetext{
${ }^{10}$ LUFT. Múltipla escolha, p. 78.

11 "If women allow themselves to be consoled for their culturally determined lack of access to the modes of intellectual debate by the invocation of hypothetical great goddesses, they are simply flattering themselves into submission (a technique often used on them by men). All the mythic versions of women, from the myth of the redeeming purity of the virgin to that of the healing, reconciling mother, are consolatory nonsenses; and consolatory nonsense seems to me a fair definition of myth, anyway. Mother goddesses are just as silly a notion as father gods. If a revival of the myths of these cults gives women emotional satisfaction, it does so at the price of obscuring the real conditions of life. This is why they were invented in the first place." (CARTER. The sadeian woman and the ideology of pornography, p. 5, tradução nossa.)

${ }^{12}$ STEVENS. Maternidade e feminismo: diálogos na literatura contemporânea, p. 18.
} 
negra, a mãe genética, etc.”. ${ }^{13}$ Percebe-se que a autora menciona, porém sem se aprofundar muito em temáticas do grotesco feminino, formas de maternidade percebidas como desviantes por não corresponderem às normas tradicionais. Tais modelos de maternidades não convencionais são retratados nas obras de Carter, Luft e Swan aqui comparadas.

\section{O FEMINISMO E A CRÍTICA À MATERNIDADE IDEALIZADA}

Após o suicídio de seu marido, em 1970, a escritora, ensaísta e ativista política Adrienne Rich declara-se lésbica e escreve duas influentes obras críticas sobre a maternidade que ainda causam um misto de antipatia e de respeito entre os acadêmicos: Of Woman Born: Motherhood as Experience and Institution [Nascido de mulher: maternidade como experiência e como instituição], de 1976, e On Lies, Secrets and Silence [Sobre mentiras, segredos e silêncio], de 1979. Em seus trabalhos críticos, Rich procura se distanciar da imagem idealizada da mulher que se torna mãe e critica "o solitário confinamento de uma vida doméstica juntamente com crianças pequenas”, ${ }^{14}$ percebendo a maternidade como um sistema no qual instituições estabelecidas por homens regulam o poder reprodutivo das mulheres.

Rich se recusa a compactuar com aqueles que idealizam a posição da mãe e ignoram a violência praticada nessa instituição patriarcal denominada maternidade. Em sua análise, duas correntes distintas são destacadas: a maternidade como uma experiência possível e profunda para as mulheres e a maternidade como identidade impingida e como instituição política em que as mulheres são vistas primariamente como mães, esperando-se delas que sejam felizes com essa função, sem que haja ambivalências. Ela acrescenta a esse raciocínio que "ser 'diferente' - uma não mãe, uma mãe solteira, uma mãe lésbica - é tornar-se um ser desviante, 'fora da lei', 'anormal' ". ${ }^{15}$ Ao invocar a experiência pessoal e individual da maternidade e contrastá-la com a maternidade como instituição, Rich identifica “a Matriz Maternal”16 como delineada pelas pressuposições sancionadas culturalmente e pelos sistemas reguladores coercivos que restringem a mulher ao papel de mãe. Nas palavras de Rich:

\footnotetext{
${ }^{13}$ STEVENS. Maternidade e feminismo: diálogos na literatura contemporânea, p. 18.

14 “(...) the solitary confinement of a life at home enclosed with young children (...).” (RICH. Of Woman born: motherhood as experience and institution, p. 279, tradução nossa.)

15 “(...) to be 'different' - a non-mother, a single mother, a mother who is lesbian - is to be deviant, 'outside the law', 'abnormal'.” (RICH. On lies, secrets and silence: selected prose -1966-1978, p. 196-197, tradução nossa.)

16 “(...) the Maternal Matrix (...).” (RICH. Of Woman born: motherhood as experience and institution, p. 61 , tradução nossa.)
} 
Cada mãe deve entregar seus filhos, dentro de alguns anos de seu nascimento, ao sistema patriarcal de educação, de lei, de religião, de códigos sexuais. De fato, espera-se dela que os prepare para entrarem nesse sistema. (...) O patriarcalismo depende da maternidade para agir como uma influência conservadora, incutindo nos futuros adultos os valores patriarcais, mesmo nos primeiros anos de vida, quando a relação mãe-filho pode parecer a mais individual e particular. (...) Certamente o patriarcalismo criou imagens do arquétipo Mãe que reforçam o conservadorismo da maternidade e a convertem em energia para a renovação do poder masculino. ${ }^{17}$

Percebe-se que a autora entende a reprodução humana como um mecanismo de perpetuação dos valores patriarcais, uma vez que cada criança irá desempenhar o seu papel social quando adulta. Fica implícito nesse raciocínio que a mãe se vê forçada a guiar seus filhos para serem reprodutores dos valores cristalizados de poder, nos quais as meninas estão fadadas a permanecerem em um ciclo em que a maternidade não é controlada pelas mulheres, mas, sim, pelos valores ditados pela matriz maternal.

Simone de Beauvoir também critica a maternidade como condição sine qua non para a felicidade e o sentimento de completude feminino. Em seu influente livro O segundo sexo, de 1949, a autora afirma que "gravidez e maternidade são vividas de maneira muito diferente entre as mulheres, podendo surgir sentimentos de revolta, resignação, satisfação, ou mesmo, entusiasmo". ${ }^{18}$ Ela ainda defende que "as decisões e os sentimentos confessados da jovem mãe nem sempre correspondem a seus desejos profundos”, podendo ocorrer de a mãe mascarar sua insatisfação no lar com um semblante de felicidade. Mesmo quando "o filho se apresenta como uma riqueza no seio de uma vida feliz, ou pelo menos equilibrada”, este não deveria "limitar o horizonte da mãe”. Contrariando a visão patriarcalista e idealizada da maternidade, Beauvoir defende que a mulher "só pode consentir em dar vida se a vida tem um sentido; não poderia ser mãe sem tentar desempenhar um papel na vida econômica, política, social". 19

O modelo tradicional de maternidade é duramente criticado por Beauvoir, por colocar a mulher em uma posição social aquém à do homem. Em suas palavras:

\footnotetext{
17 "Every mother must deliver her children over within a few years of their birth to the patriarchal system of education, of law, of religion, of sexual codes; she is, in fact, expected to prepare them to enter that system. (...) Patriarchy depends on motherhood to act as a conservative influence, imprinting future adults with patriarchal values even in those early years when the mother-child relationship might seem most individual and private. (...) Certainly it has created images of the archetypal Mother which reinforce the conservatism of motherhood and convert it to an energy for the renewal of male power." (RICH. Of woman born: motherhood as experience and institution, p. 61, tradução nossa.)

${ }^{18}$ BEAUVOIR. O segundo sexo: volume 2 - a experiência vivida, p. 258.

${ }^{19}$ BEAUVOIR. O segundo sexo: volume 2 - a experiência vivida, p. 292.
} 
É uma mistificação sustentar que a mulher se torna, pela maternidade, a igual concreta do homem. (...) Falou-se também muitíssimo dos direitos sagrados da mãe, mas não foi como mãe que as mulheres conquistaram o direito de voto; a mãe solteira é ainda desprezada; é somente no casamento que a mãe é glorificada, isto é, na medida em que permanece subordinada ao marido. Enquanto este permanece o chefe econômico da família, embora ela se ocupe muito mais dos filhos, eles dependem muito mais dele do que dela. É por isso que, como vimos, a relação da mãe com os filhos se acha estreitamente comandada pela que mantém com o esposo. ${ }^{20}$

O excerto acima mostra que o ideal do eterno feminino, na verdade, reforça o poder masculino, que se mantém no controle da estrutura familiar. Tal estrutura subjuga as esposas a tarefas tidas por Beauvoir como menos interessantes, por estarem afastadas do poder político. A autoridade está na voz daqueles que detêm o capital, enquanto os outros membros da família, em especial a esposa, dependem do aval masculino para viverem ativamente na sociedade. A autora finaliza seu raciocínio sobre a maternidade com um tom fatalista, criticando o fato de “entre os árabes, os índios e muitas populações rurais” a mulher ser “apenas uma criada, apreciada segundo o trabalho que fornece e substituída sem lamentações caso desapareça”. A mãe encontraria sua única condição de sobrevivência digna entregandose à “dedicação apaixonada e tirânica pela família”, ${ }^{21}$ no ambiente definido mais tarde por Friedan como o campo de concentração confortável.

Faz-se necessária a percepção dos conceitos feministas das décadas de 1950, 1960 e 1970, nos quais a posição da mulher subjugada ao seu cônjuge é criticada, para que as análises das maternidades grotescas presentes em Noites no circo, de Angela Carter, Exílio, de Lya Luft, e The biggest modern woman of the world, de Susan Swan, sejam mais bem apreendidas. Fiona Carson afirma que "[d]esafiar a representação ideológica dominante da feminilidade foi uma pedra angular da segunda onda da teoria feminista”. ${ }^{22}$ Os conceitos de feminismo atuais são um pouco diferentes dos preconizados na primeira onda feminista, porém, os romances aqui comparados foram escritos na década de 1980, e estão ainda sob os efeitos desses questionamentos. No entanto, é importante lembrar que Noites no circo e The Biggest Modern Woman of the World enfocam personagens femininas grotescas que estão inseridas em um contexto de sociedades tradicionais e tipicamente patriarcais do século 19. Mesmo assim, a protagonista de Carter, Fevvers, não se submete aos valores de maternidade idealizada e repudia a ideia do casamento tradicional. A protagonista de Luft tem relações

\footnotetext{
${ }^{20}$ BEAUVOIR. O segundo sexo: volume 2 - a experiência vivida, p. 293.

${ }^{21}$ BEAUVOIR. O segundo sexo: volume 2 - a experiência vivida, p. 294.

22 "Challenging the dominant ideological representation of femininity was a cornerstone of second wave feminist theory.” (CARSON. Feminism and the body, p. 118, tradução nossa.)
} 
conflitantes com sua mãe, que é alcoólatra e suicida, e com seu filho, cuja guarda perdera para seu ex-marido. Dessa forma, a narrativa apresenta duas gerações de mães tidas como grotescas, que falham por não serem exemplares de sustentação do “mito da família feliz”. Na obra de Swan a giganta, simbolicamente, fica maior que o espaço doméstico, que a restringe por causa de sua altura, e sai de casa para se exibir em circos de horrores. Ela vive uma contradição porque, mesmo desejosa de seguir os modelos patriarcais de maternidade, sua condição de mulher grotesca a impossibilita de realizar seus planos. No dia do seu casamento ela perde a voz, o pai biológico de seus bebês não é o seu marido e, nas duas vezes em que fica grávida, seus filhos não sobrevivem.

Também é interessante perceber nessas obras que as figuras maternas desempenham funções mais significativas do que aquelas das mães biológicas, principalmente em Noites no circo e em Exílio. Fevvers desconhece seus pais e respeita a dona da casa de prostituição que a acolhera, Mamãe Nelson, como se fosse sua mãe. Logo depois de sua morte, a protagonista alada se vê amparada pela prostituta Lizzie. A protagonista de Luft, quando criança, tem como figura materna a Irmã Cândida, que trabalha em seu colégio. Esse relacionamento é abruptamente interrompido por suspeitas de abuso sexual praticado pela religiosa, que, na voz da protagonista, não ocorreu. As obras de Carter, Luft e Swan desafiam os códigos patriarcais de maternidade criticados por muitas publicações feministas das décadas que precedem os romances aqui comparados, ilustrando maternidades que se distanciam dos valores tradicionais femininos.

\section{INVERTENDO AS REPRESENTAÇÕES IDEOLÓGICAS DOMINANTES}

Segundo Luiz Nazário, ${ }^{23}$ em Da natureza dos monstros, “o grande boom de mulheresmonstros [no cinema] deve-se à subversão dos papéis sexuais tradicionais” pela qual algumas personagens se monstrificam por retraírem sua feminilidade. O autor também ressalta que "tal como a masculinidade, a feminilidade é uma construção cultural”, e que, por consequência, “os homens que não encontram ou renegam sua masculinidade são estigmatizados, as mulheres que divergem, mental ou biologicamente, do eterno feminino, tendem a ser monstrificadas”. ${ }^{24}$ Nesse contexto, a mulher que assume seu papel social feminino, no qual a

\footnotetext{
${ }^{23}$ NAZÁRIO. Da natureza dos monstros, p. 125.

${ }^{24}$ NAZÁRIO. Da natureza dos monstros, p. 117.
} 
maternidade se destaca, corrobora o que Margaret Miles define como "imagens positivas de mulheres”. ${ }^{25}$ Nas palavras de Miles:

Imagens "positivas" de mulheres - ou seja, imagens de mulheres socialmente aceitáveis, mulheres "boas" sob a perspectiva do governo do coletivo masculino - freqüentemente funcionam não como "recompensas" para mulheres, mas como mensagens prescritivas. Imagens positivas definem com o que a "bondade" feminina se parece e compelem as mulheres a imitarem as qualidades de tais imagens. As imagens positivas das mulheres, então, têm uma função importante, mesmo, ou especialmente, nas sociedades mais misóginas. Da mesma forma, a literatura misógina consistentemente enfoca e valoriza mulheres boas; freqüentemente um senso ilusoriamente enfatuado de superioridade da mulher justifica o ataque do autor às mulheres que não correspondem a esse ideal, como acontece inevitavelmente com a maioria delas. Assim, os elogios à "superioridade" feminina podem funcionar para justificar a difamação das mulheres. ${ }^{26}$

Miles argumenta que as sociedades misóginas, para sustentarem a supremacia masculina, definem rigidamente as qualidades femininas que devem ser copiadas pelas mulheres que desejam ser aceitas como normais. Para que um grande número de pessoas sustente tais padrões, criam-se dispositivos reguladores de conduta, nos quais a imagem positiva de mulheres, presente em grande parte na arte e na literatura machistas, dita as regras de comportamento que reforçam o tal modelo cristalizado de poder.

Miles e Julia Kristeva percebem que tal imagem positiva feminina sustentada por muitas culturas ocidentais é representada pela figura da Virgem Maria, que regula, desde a Idade Média, as configurações “aceitáveis de aparência, atitudes e comportamento prescritas para as mulheres”. ${ }^{27}$ Para Miles, a pintura de Carlo da Camerino, The Madonna of Humility with the Temptation of Eve [Nossa Senhora da Humildade com a tentação de Eva], do final do século 14, é um referencial apropriado para ilustrar a justaposição “da 'mulher boa' com a

\footnotetext{
${ }^{25}$ MILES. Carnal knowing: female nakedness and religious meaning in the Christian West, p. 139.

26 “'Positive' images of women - that is, images of socially approved women, 'good' women from the perspective of the governing male collective - often function not as 'rewards' for women, but as prescriptive messages. Positive images define what female 'goodness' looks like and urge women to imitate the qualities of these images. Positive images of women, then, play a very important role, even or especially, in the most misogynist societies. Similarly, misogynist literature consistently pictures and praises good women; frequently an unrealistically inflated sense of women's superiority justifies the author's attack on women who fall from this ideal as most women inevitably must. Praise for the 'superiority' of women therefore can operate to justify vilification of women." (MILES. Carnal knowing: female nakedness and religious meaning in the Christian West, p. 139, tradução nossa.)

27 “(...) acceptable appearance, attitudes, and behavior prescribed for women.” (MILES. carnal knowing: female nakedness and religious meaning in the Christian West, p. 139, tradução nossa.)
} 
‘mulher má, ”. ${ }^{28}$ Três quartos da parte superior da referida pintura são ocupados pela figura da Virgem Maria, contrastando com a figura estereotipada de Eva, nua, segurando a maçã mordida, e com a serpente, ambas posicionadas estrategicamente na parte inferior do quadro. A crítica enfoca em sua análise da ilustração que a "representação do corpo da Virgem está limitada diretamente às partes que servem para sustentar e alimentar a criança”, ${ }^{29}$ sugerindo que a maternidade é um ideal necessário a ser almejado pelas mulheres que desejam ser boas.

A teoria do abjeto de Julia Kristeva, unida às teorias do grotesco, são referências teóricas necessárias para este estudo comparativo, uma vez que a maternidade na esfera grotesca se apresenta, em muitos casos, distante dos modelos tradicionais preconizados nas imagens costumeiras de perfeição familiar. Criando um neologismo, característica comum a seus textos, Kristeva publica em 1977 o controverso “Hérethique de l'amour” - aglutinando as palavras francesas hérétique [herege] com éthique [ética] -, no qual a psicanalista mescla conceitos da maternidade na psicanálise com a óptica teológica católica, em que a figura da Virgem Maria funciona como um placebo criado para atenuar a angústia humana perante a morte. Esse polêmico texto foi publicado como "Stabat Mater" em Histórias de amor, de 1983. O título em latim se refere a um hino em louvor à Virgem Maria no qual se canta “Stabat mater dolorosa juxta crucem lacrimosa, dum pendembat filius (...)” [Estava a mãe dolorosa chorando junto à cruz da qual seu filho pendia.]

Assemelhando-se aos textos críticos feministas de Rich, Friedan e Beauvoir, a psicanalista inicia o seu texto afirmando que “a única função do 'outro sexo”” é ser mãe e que “vivemos numa civilização em que a representação consagrada (religiosa ou leiga) da feminidade é absorvida pela maternidade. ${ }^{30}$ Em seu ponto de vista, “quando o feminismo reivindica uma nova representação da feminidade, ele parece identificar a maternidade com esse equívoco idealizado e recusando a imagem e seus abusos, contorna a experiência real que tal fantasma oculta”. 31

O raciocínio psicanalítico de Kristeva, no qual o corpo do filho rejeita o corpo da mãe para tornar-se um ser independente, une-se de certa forma às vozes de Friedan, Rich e Beauvoir para questionar o estereótipo idealizado da maternidade. Nas palavras de Kristeva:

\footnotetext{
28 “(...) the 'good woman' and the 'evil woman' (...).” (MILES. carnal knowing: female nakedness and religious meaning in the Christian West, p. 139, tradução nossa.)

29 "Depiction of the Virgin's body is limited to parts directly in the service of bearing and nourishing the child." (MILES. Carnal knowing: female nakedness and religious meaning in the Christian West, p. 139, tradução nossa.)

${ }^{30}$ KRISTEVA. Histórias de amor, p. 269. (grifos da autora)

${ }^{31}$ KRISTEVA. Histórias de amor, p. 269.
} 
Poderíamos, sem dúvida, tentar abordar este ponto obscuro que é a maternidade para uma mulher, ouvindo mais atentamente do que nunca o que dizem as mães hoje em dia, através de suas dificuldades econômicas e, para além da culpa que um feminismo demasiado existencialista legou, de suas indisposições, insônias, alegrias, raivas, dores e felicidades $(\ldots)^{32}$

No excerto acima, a psicanalista tenta desmistificar a figura da mãe idealizada, expondo o fato de o gozo e a dor comporem o quadro da maternidade humana. McAfee observa também que em “Stabat Mater” Kristeva percebe que as mulheres contemporâneas ainda almejam serem mães, mas que "não desejam ser masoquistas abnegadas, uma vez que essa representação de maternidade exige delas uma renúncia de seus próprios desejos”.33 Kristeva se distancia dos conceitos essencialistas nos quais propriedades e atributos universais de maternidade impedem que a mulher se liberte da conotação negativa que algumas feministas frequentemente atribuem ao papel materno. Como bem nos lembra McAfee:

Então, nós precisamos das mães. Novamente, essa afirmação parece
essencialista, um bom combustível para os conservadores. Mas Kristeva não
faz generalizações das mulheres. (...) Kristeva não faz um chamado, como
alguns críticos dizem, à "maternidade compulsória”, na qual é uma
obrigação da mulher ter filhos. De fato, as mulheres que têm filhos estão
dando um presente à humanidade, garantindo nossa sobrevivência. O ponto
principal de Kristeva é que nós precisamos pensar melhor em uma nova
representação de maternidade.

Kristeva percebe que a maternidade compulsória de Rich é uma noção muito radical, e que existe a possibilidade de a mulher ser mãe e não ser uma pessoa abnegada. "Stabat Mater" questiona o modelo idealizado de maternidade e o estereótipo de família feliz, em que as crianças, necessariamente filhos biológicos de um casal heterossexual, vivem em completa harmonia. As obras de Carter, Luft e Swan também desmistificam esses ideais de perfeição.

O padrão tradicional de família não está presente em Noites no circo, cuja narrativa enfoca uma mulher alada que desconhece suas origens e reconhece como mãe não sua progenitora, mas, sim, uma cafetina que a acolhe como se fosse sua filha. A personagem

\footnotetext{
${ }^{32}$ KRISTEVA. Histórias de amor, p. 289.

33 " (...) they do not want to be self-abnegating masochists, and, given that the representation of motherhood calls on them to renounce their own desires (...).” (McAFEE. Julia Kristeva: Rutledge critical thinkers, p. 83, tradução nossa.)

34 "So, we need mothers. Again, this might seem essentialist, good fuel for conservatives. But Kristeva does not make generalizations about women themselves. (...) Kristeva is not calling for, as some critics have put it, 'compulsory maternity,' that it be a woman's duty to bear children. Yes, the women who do bear children are providing a gift to humanity, ensuring our survival. Kristeva's main point is that we need a better way of thinking, a new representation of motherhood." (McAFEE. Julia Kristeva: Rutledge Critical Thinkers, p. 86-87, tradução nossa.)
} 
central de Exílio e seu irmão respondem ao modelo tradicional de família, no qual, unidos ao pai e à mãe, estruturam tal concepção. No entanto, a cisão abjeta do corpo materno ao corpo dos filhos encontra-se comprometida, uma vez que a mãe cometera suicídio na presença dos filhos e o mais jovem deles chega mesmo a beber do sangue de sua mãe, episódio responsável por comprometer sua sanidade mental. Por sua vez, a giganta de Swan corrompe o modelo tradicional de família por sua incapacidade para gerar filhos saudáveis com o seu marido, Martin Bates.

\section{MATERNIDADES GROTESCAS}

É possível perceber uma gama de possíveis conceitos de maternidades grotescas na literatura. Tais exemplos de maternidades desviantes, como bem nos lembra Susana Bornéo Funck, em "Representações da maternidade e da paternidade na literatura feminista contemporânea” (1999), geralmente são providos de uma “força revolucionária e não mais como modo de manutenção do status quo" 35 e, a meu ver, se opõem a ilustrações como a de Nossa Senhora da Humildade. Essa crítica a certos valores tradicionais, como o da maternidade perfeita e o da família estereotipadamente feliz, estão presentes nas obras aqui comparadas.

Cristina Stevens enumera algumas possibilidades de maternidade que escapam do modelo previsto como normal ou tradicional, representado por um casal heterossexual e filhos provenientes desse matrimônio. ${ }^{36}$ Funck também enfatiza que

conforme o projeto feminista desvia seu olhar da igualdade para a diferença, em meados da década de 70, e o resgate de uma tradição cultural feminina começa a atrair a atenção de escritoras e de críticas, testemunhamos uma nova alteração no paradigma ficcional. ${ }^{37}$

Percebem-se nas obras de Carter, Luft e Swan, aqui analisadas, alguns questionamentos a tais modelos idealizados de família. Para completar ainda mais a lista de maternidades alternativas proposta por Stevens, as obras de Carter e de Luft apresentam mulheres que, mesmo não sendo progenitoras, cuidam de crianças que não são geneticamente suas, constituindo um exemplo de figuras maternas, como previsto na psicanálise. Em

\footnotetext{
${ }^{35}$ FUNCK. Representações da maternidade e da paternidade na literatura feminista contemporânea, p. 304.

${ }^{36}$ STEVENS. Maternidade e feminismo: diálogos na literatura contemporânea, p. 18.

${ }^{37}$ FUNCK. Representações da maternidade e da paternidade na literatura feminista contemporânea, p. 303.
} 
contrapartida, a obra de Swan desmantela o projeto patriarcal apresentando um modelo feminino cujo corpo não é capaz de sustentar tais conceitos normalizadores.

A estudiosa das obras carterianas, Heather Johnson, afirma que Noites no circo revela “um apelo político, proveniente de parte do feminismo que emergiu de meados dos anos 1960 em diante para desafiar as representações das mulheres, questionar visões restritivas do real e, assim, abrir novas possibilidades políticas”. ${ }^{38}$

Fevvers tem como uma de suas inúmeras denominações artísticas "a grande artista da vigarice na história do mundo", 39 tem em seu corpo grotesco a resposta para fugir dos ambientes que a aprisionam: asas. Contrastando com a Sophie sadiana, Fevvers aprende a almejar a liberdade e não aceita que lhe aprisionem a conceitos tradicionais de comportamento feminino. A figura masculina que acompanha Fevvers, Jack Walser, é diversas vezes ludibriada por essa mulher que ora se apresenta como "Vitória Alada" 40 e ora como “Anjo da Morte”. ${ }^{41}$ Recebendo várias denominações e rótulos, os quais ela aceita e ao mesmo tempo rejeita, Fevvers mostra que o significado de seu nome original, Sophie, isto é, sabedoria, rege muitas de suas ações, e que ela não se vê como vítima nem deseja se adequar a padrões de perfeição feminina. Em entrevista ao repórter californiano, ela afirma que foi “chocada”, rompendo, assim, com um dos paradigmas da maternidade. Nas palavras da protagonista:

Chocada. Por quem, eu não sei. Para mim, meu senhor, quem me pôs é tanto um mistério quanto a natureza da minha concepção, meu pai e minha mãe inteiramente desconhecidos para mim e, mais do que isso, diriam alguns, desconhecidos para a natureza. Mas saí do ovo e fui colocada naquela cesta de cascas quebradas e palha em Whitechapel na porta de uma determinada casa, sabe o que quero dizer? ${ }^{42}$

Pelo excerto acima, mesmo sendo possível que Fevvers tenha inventado uma narrativa sobre suas origens para reforçar a sua performance grotesca de mulher alada no circo e, assim, impressionar Walser, percebe-se que ela constrói um modelo de família diferente do tradicional. Ela vacila entre o humano e o animal, desafiando a natureza e a ciência por ser

\footnotetext{
38 “ (...) a political urge, born in part out of the feminism that emerged from the mid-1960s onwards to challenge representations of women, question restrictive views of the real and, thereby, open up new political possibilities.” (JOHNSON. Metafiction, magical realism and myth, p. 70, tradução nossa.)

${ }^{39}$ CARTER. Noites no circo, p. 108.

${ }^{40}$ CARTER. Noites no circo, p. 43.

${ }^{41}$ CARTER. Noites no circo, p. 82.

${ }^{42}$ CARTER. Noites no circo, p. 24. (grifo da autora)
} 
uma mulher que saiu de um ovo. Fevvers corrompe a ideia estereotipada de família por declarar desconhecer suas origens, afirmando que foi “criada num bordel” e que está “orgulhosa disso" 43 - quando o esperado em sociedades conservadoras seria desejar omitir esses fatos que, para alguns, são vergonhosos. Ao contrário, Fevvers chama a casa de prostituição que a lhe deu abrigo de "Academia de Mamãe Nelson”. ${ }^{44}$ O título de "academia” não é por acaso. Mamãe Nelson, na visão de Fevvers, não liderava prostitutas, mas, sim, "sufragistas" 45 que defendiam "Votos para as Mulheres”, e sua casa era um ambiente educacional, repleto de livros e propício à reflexão, ao aprendizado e ao questionamento:

Deixe-me lhe contar que do lado de dentro da porta de Mamãe Nelson era um mundo inteiramente feminino. Até mesmo o cachorro que ficava de guarda era uma cadela e todos os gatos eram fêmeas, uma ou outra sempre para ter filhotes ou recém-parida, de modo que um subtexto de fertilidade subscrevia a cintilante esterilidade do prazer da carne disponível dentro da academia. Dentro daquelas paredes a vida era governada por uma razão doce e amorosa. Nunca vi um único tapa trocado entre qualquer das integrantes da irmandade que me criou nem ouvi uma palavra zangada ou uma voz alterada com raiva. (...) o que se seguia depois que elas guardavam os livros era apenas pobres moças ganhando a vida, pois, embora alguns clientes possam jurar que as prostitutas fazem isso por prazer, é apenas para aliviar as suas próprias consciências, para que se sintam menos bobos quando entregam dinheiro grosso por prazer que não tem existência verdadeira a menos que seja dado gratuitamente. Oh, realmente! Nós sabemos que só vendemos simulacros. Nenhuma mulher iria virar a barriga para o comércio a menos que fosse obrigada pela necessidade econômica, meu senhor. ${ }^{46}$

Ao contrário do estereótipo de violência e de degradação comuns aos bordéis, a Academia de Mamãe Nelson é um lugar seguro, limpo e acolhedor, no qual Fevvers cresce feliz sob os cuidados de suas colegas prostitutas que a adotaram, contrapondo-se ao museu de horrores de Madame Schreck. O nome de Mamãe Nelson é bastante significativo. As prostitutas que trabalham em sua casa não são percebidas por ela como empregadas, e sim como filhas. Mamãe Nelson é a figura materna de todas que habitam sua academia, que é considerada por Fevvers como uma irmandade. Outro aspecto interessante a ser analisado é que a maternidade humana, tradicionalmente ilustrada pela mãe que amamenta, não existe nesse contexto, e tal papel fica delegado aos animais, que são exclusivamente fêmeas e se reproduzem com regularidade. Finalmente, por serem mulheres educadas, as prostitutas que

\footnotetext{
${ }^{43}$ CARTER. Noites no circo, p. 25.

${ }^{44}$ CARTER. Noites no circo, p. 67.

${ }^{45}$ CARTER. Noites no circo, p. 45.

${ }^{46}$ CARTER. Noites no circo, p. 45-46.
} 
trabalham para Mamãe Nelson não encaram a prostituição como um trabalho degradante, e sabem que vendem representações do amor verdadeiro. Nesse ambiente em que Fevvers cresce, o modelo tradicional de mãe é substituído por mulheres que desempenham a função de mãe, sendo que Mamãe Nelson é a mãe substituta de todas as mulheres da academia. Fevvers, por ser a mais jovem do bordel, é cuidada “por todas as moças”. 47

\section{PIETÀS ÀS AVESSAS}

Umberto Eco observa que, desde a Antiguidade, tanto a beleza quanto a feiura são definidas "em relação a um modelo estável”. ${ }^{48}$ Pode-se dizer que "o feio é o contrário do belo”, podendo, por exemplo, se configurar em "um ser humano com uma cabeça enorme e pernas curtíssimas”. ${ }^{49}$ Esse modelo idealizado com o qual o feio contrastava, ao qual Eco faz menção, será sempre o arquétipo normalizador do qual o ser grotesco irá se distanciar. Margaret Miles tenta categorizar os possíveis mecanismos para a identificação do grotesco nas artes que afrontam tais arquétipos de perfeição, e afirma que "os três recursos retóricos e pictóricos mais relevantes que contribuem para apresentação grotesca são: caricatura, inversão e hibridização”. ${ }^{50}$ Dessa forma, as caracterizações grotescas são compostas pelo reverso do que está tradicionalmente representado. Margaret Miles observa que a mulher grotesca é representada pelo contrário do modelo de perfeição feminina medieval, eternizado pela religião católica nas múltiplas iconografias da Virgem Maria.

Nas obras de Luft e de Swan, esses conceitos de maternidade e a condição da mulher inserida em uma cultura patriarcal encontram-se amalgamados nas protagonistas, que, de certa forma, se assemelham à figura pertencente ao imaginário católico de Nossa Senhora das Dores. A personagem afirma que sente a "dor de uma faca, de muitas facas cravadas no coração o tempo todo, desde a patética descoberta” de que é traída por seu marido. ${ }^{51}$ Essa metáfora de facas cravadas no coração, utilizada pela personagem de Exílio, remete diretamente à imagem de Nossa Senhora das Dores, ou Mater Dolorosa, representada por sete espadas que perpassam o coração da Mãe de Deus, sendo cada perfuração correspondente a

\footnotetext{
${ }^{47}$ CARTER. Noites no circo, p. 14.

${ }^{48}$ ECO. História da feiúra, p. 15.

${ }^{49}$ ECO. História da feiúra, p. 16.

50 "Three major rhetorical and pictorial devices contribute to grotesque presentation: caricature, inversion, and hybridization.” (MILES. Carnal knowing: female nakedness and religious meaning in the Christian West, p. 155, tradução nossa.)

${ }^{51}$ LUFT. Exílio, p. 112.
} 
uma dor específica de Maria vinculada a sua condição de mãe. Nossa Senhora das Dores também é frequentemente representada com uma expressão de dor diante da cruz contemplando o filho morto, a partir da qual surgiu o hino medieval Stabat Mater; ou então segurando Jesus morto nos braços, após o seu descendimento da cruz, dando assim origem às imagens das Pietàs.

Exílio e The biggest modern woman of the world apresentam momentos marcantes nos quais são ilustradas cenas da Pietà às avessas. A maternidade grotesca na obra de Swan se opõe à figuração tradicional da Pietà por mostrar uma giganta segurando o corpo de seu filho monstro que acaba de morrer. Na obra de Luft, a inversão da figuração de Maria das Dores ocorre quando o amante da protagonista, Antônio, segura o corpo de seu filho doente mental, caracterizando assim um Pater Dolorosus. ${ }^{52}$ Anna Swan, no momento do nascimento de seu segundo bebê, e Antônio, quando recebe a visita da protagonista em sua residência, podem ser vistos como releituras grotescas de Nossa Senhora das Dores.

Um dos momentos dolorosos pelos quais passa a giganta ocorre durante o parto de sua segunda gravidez. Por se tratar de um bebê-monstro, o procedimento dura três dias para ser concluído e a criança vive por apenas 11 horas. Seu óbito é atribuído às suas “dificuldades genéticas”. ${ }^{53}$ O nascimento da criança é relatado por Anna, em seu diário, e pelos médicos Dr. Beach e Dr. Robinson, em seus respectivos relatórios médicos. Sob a óptica de Anna:

Eu nem era capaz de sentir a criança presa na minha vagina gigante. Será esse o sofrimento da mulher normal durante o parto? (...) Eu senti quando os médicos lutavam entre minhas coxas abertas. (...) O meu filho exausto emergiu - sua aparência era de um verdadeiro gigante devido às suas proporções - e eu o levantei para mostrá-lo a Angus, mas ele tinha ido embora. Então eu o apertei sobre meus seios que vazavam, grata por ele não ser natimorto. (...) Babe parecia extremamente fraco apesar de seu descomunal tamanho o qual o Dr. Beach me informou que faria história na medicina: comprimento $76 \mathrm{~cm}$, peso $10,89 \mathrm{~kg}$, circunferência do peito 60 $\mathrm{cm}$, nádegas $68 \mathrm{~cm}$, cabeça $48 \mathrm{~cm}$, e os pés $13,5 \mathrm{~cm}$. Seu nariz e suas bochechas estavam horrivelmente esmagados por causa de seu percurso de três dias para fora de mim, mas os médicos achavam que ele se parecia com Martin - e ele se parecia mesmo, de um jeito triste e deformado. ${ }^{54}$

${ }^{52}$ LUFT. Exílio, p. 127.

53 “genetic difficulties”. (SWAN. The biggest modern woman of the world, p. 327, tradução nossa.)

54 "I could not even feel the child trapped in my giant vagina. Is this how the normal female goes through birth? (...) I felt as the doctors struggled between my spread thighs. (...) My exhausted son emerged - a true giant in his physical proportions from the looks of him - and I held him up to show Angus but Angus was gone. Then I clasped him to my leaking breasts, grateful he was not stillborn. (...) Babe appeared to me extremely weak despite his astounding size which Dr. Beach informed me would make medical history: length 30 inches, weight 233/4 pounds, breast 
O excerto mostra a angústia de Anna, que não mais se orgulha de sua condição de giganta e compara sua maternidade grotesca com a das mulheres normais. Segundo o atestado de óbito, a criança morre depois do parto devido a sua má formação congênita. No relatório médico de Dr. Beach aparecem alguns detalhes que não estão presentes nos registros de Anna, como o fato de a cabeça do bebê ter quebrado o fórceps de madeira construído pelo médico, que aquele parto fora "o pior caso" 55 de sua carreira e que o filho de Anna era "o maior do país [Estados Unidos] e possivelmente do mundo!”56

Anna inicia a sua narrativa como giganta de circo de horrores, sugerindo que seu corpo desproporcional lhe confere poder e que ela é feliz com sua magnitude. O final da obra de Swan termina com o fracasso dela em ser mãe, em ser vista como uma normal em sua comunidade, chegando mesmo a desculpar-se ao médico por ser uma giganta. ${ }^{57}$ Seu esforço para se normalizar através da maternidade é em vão e o seu destino de ser uma curiosidade de museu de horrores é reforçado na frase registrada pelo Dr. Beach: “A casa [de Anna e de Martin] era exatamente um palco." ${ }^{58} \mathrm{O}$ espetáculo da maternidade grotesca da giganta tem seu momento máximo quando Anna segura em seus braços o corpo de seu filho morto:

“Seu bebê não está respirando.” [Fotógrafo] “Do que é que você está
falando, cara? Meu filho está dormindo,” Martin gritou. "Traga o Babe
aqui,” eu [Anna] ordenei. O fotógrafo obedeceu, carregando Babe com os
braços estirados como se minha criança fosse uma fonte de doença. Antes
que eu pudesse segurá-lo, Martin tomou Babe do fotógrafo e começou a
contar os seus dedos das mãos e os seus dedos dos pés. "Viu! Vivo e
perfeitamente formado,” o gigante vociferou ao fotógrafo amedrontado. “Eu
não vou fotografar um cadáver,” disse o fotógrafo. Eu comecei a chorar
porque eu vi que Babe não estava se mexendo nos braços de Martin e sua
língua se estendia sem vida para fora de sua boca aberta. Martin parou de
gritar e docilmente trouxe a criança inerte a mim. Eu o embalei em meu
peito e mandei Martin buscar os médicos que dormiam no andar de cima.
"Você tiraria uma foto do meu filho?” eu pedi. "Ela será a minha única
recordação dele”. O homenzinho se arrastou enrubescido e suavemente disse
sim (...). Eu me deitei no quarto com Babe, feliz por tê-lo comigo pela
última vez, e me senti resignada. A morte dele acabou com o sonho de

circumference 24 , breech 27 , head 19 , and the feet $51 / 2$ inches. His nose and cheeks were badly squashed from his three-day journey out of me but the doctors thought he looked like Martin - and he did, in a sad and crumpled way." (SWAN. The biggest modern woman of the world, p. 325, tradução nossa.)

55 “(...) worst case (...).” (SWAN. The biggest modern woman of the world, p. 325, tradução nossa.)

56 "Largest in nation and possibly world!.” (SWAN. The biggest modern woman of the world, p. 329, tradução nossa.)

${ }^{57}$ SWAN. The biggest modern woman of the world, p. 328.

58 "The house was quite a showplace." (SWAN. The biggest modern woman of the world, p. 327, tradução nossa.) 
Martin de ter uma raça de gigantes e aniquilou minha esperança de que finalmente, algum dia, eu pudesse ter uma conexão com esse mundo estranho no qual eu fui lançada. ${ }^{59}$

Os gigantes percebiam o nascimento desse filho como uma possível saída para se normalizarem. Martin acreditava que vivendo em meio a outros gigantes ele poderia ser aceito como apenas mais um integrante do grupo, e não como uma aberração que se destaca da maioria. No entanto, esse sonho do marido de Anna camufla, na verdade, uma vontade inconsciente de não ser visto como um monstro, e ser incorporado em sua sociedade como um normal. De forma semelhante, Anna acredita que não seria mais considerada por sua comunidade como um ser grotesco se constituísse uma família aos moldes tradicionais. A realização de seu desejo dura apenas 11 horas e é, de certa forma, eternizada pela fotografia que, na verdade, mostra uma versão grotesca da Mater Dolorosa. A giganta que chora a morte de seu filho e o segura contra seu peito, com diversos ferimentos em seu corpo anormal ocorridos durante o parto, remete à imagem de Nossa Senhora da Dores.

A obra de Lya Luft também apresenta figurações grotescas da Pietà, como no capítulo seis de Exílio, "Você, Pater Dolorosus", ${ }^{60}$ quando a protagonista de Luft vai visitar o filho de seu amante, um adolescente que, semelhante a seu irmão Gabriel, também tem problemas mentais. Nessa cena, a figura da mãe chorosa é substituída por um pai cujo rosto é "grave, suplicante e triste” ${ }^{61}$ Em seus braços está o corpo de um filho que quase não vive. Nessa cena abjeta, a protagonista afirma que "apesar da repulsa e do horror”, aproxima-se do pai, segurando o corpo do filho, “fascinada”, ${ }^{2}$ Nas palavras da narradora:

59 “'Your baby's not breathing.' 'What are you talking about, man? My son is asleep,' Martin bellowed. 'Bring Babe here,' I commanded. The photographer obeyed, carrying Babe in outstretched arms as if my child was a disease object. Before I could hold him, Martin snatched Babe from the photographer and began to count his fingers and toes. 'See! Alive and perfectly formed,' the giant thundered at the frightened photographer. 'I won't photograph no corpse,' the photographer said. I began to weep for I saw that Babe wasn't moving in Martin's arms and his tongue lolled slackly out of his open mouth. Martin stopped shouting and meekly brought the inert child to me. I cradled him to my breast and sent Martin to fetch the doctors sleeping upstairs. 'Will you take a picture of my child?' I asked. 'It will be my only memento of him.' The little man shuffled and blushed and softly said yes (...). I lay in the borning room with Babe, glad to have him to myself for the last time, and felt resigned. His death ended Martin's dream for a giant race and dashed my hope that finally, someday, I might have a connection with this odd world into which I'd been thrust." (SWAN. The biggest modern woman of the world, p. 326-327, tradução nossa.)

${ }^{60}$ LUFT. Exílio, p. 127.

${ }^{61}$ LUFT. Exílio, 129.

${ }^{62}$ LUFT. Exílio, p. 131. 
No seu colo [de Antônio], atravessado como um grande bebê, um adolescente. Muito comprido, desengonçado, esquelético; um longo braço pendurado até o chão; pés magros e brancos; todo ele flácido, como se lhe faltassem músculos; a cabeça sustentada na curva do braço paterno oscilava nesse forte apoio. (...) o Menino, com dificuldades de engolir, babava-se todo, estava sujo (...). A cabeça do Menino parecia desmesurada (...). O monstruoso bebê soltou uma espécie de miado débil, e outro ruído repugnante; um cheiro fétido espalhou-se no quarto. Você [Antônio] me olhou rapidamente, dolorido e envergonhado. ${ }^{63}$

Essa imagem de Antônio descrita pela narradora, segurando seu filho de corpo grotesco, tem fortes ressonâncias com a figuração clássica de Maria segurando o corpo de Jesus morto, semelhança essa reforçada inclusive pelo título do capítulo. O Menino, como a maioria dos integrantes da Casa Vermelha, também é desprovido de nome, fato que o faz ocupar na narrativa o mundo dos seres que se distanciam dos padrões de normalidade. As funções dos pais também aparecem invertidas. Alimentar o filho em seu colo é uma função tradicionalmente feminina que em Exílio é subvertida. A mãe ausente do Menino cede seu espaço para um pai que alimenta um "bebê-monstro". A protagonista, cuja própria maternidade também se distancia do ideal feminino, rejeita compartilhar do sofrimento de seu amante. Em suas palavras: "Deixara meu próprio filho [Lucas], que me dava tantas alegrias: não poderia dar nada àquela criatura [o Menino]. Não fui médica nem mãe naqueles momentos: era uma mulher a quem a vida pregara uma peça macabra.”64 A protagonista de Luft, que acreditava retomar sua vida nos moldes tradicionais de família, casando-se com Antônio, mais uma vez se vê incapaz de se inscrever no estereótipo do ideal de mãe.

Em seus textos críticos, Luft ainda percebe que "somos ofuscados pelo danoso mito da mãe santa, da esposa imaculada e do homem poderoso" que irão produzir "filhos mais que perfeitos”. ${ }^{65}$ A realização desses mitos não se concretizam nas narrativas de Carter, Luft e Swan aqui comparadas. Tanto em Noites no circo quanto em Exílio, as mães biológicas estão ausentes, e essa lacuna é preenchida por uma amorosa figura materna que, quando morre, provoca em suas filhas adotivas sentimentos de pesar, dor e abandono. No entanto, as imagens maternas nos dois romances são distintas e mesmo opostas. Enquanto Fevvers tem como figura materna uma cafetina, considerada por alguns como uma promotora da degradação humana e do pecado, a protagonista de Luft tem como figura materna uma irmã de caridade, percebida pelos católicos como uma representante da virtude e da moral tradicional. Ambas,

\footnotetext{
${ }^{63}$ LUFT. Exílio, p. 129-130.

${ }^{64}$ LUFT. Exílio, p. 131.

${ }^{65}$ LUFT. Exílio, p. 240.
} 
Mamãe Nelson e Irmã Cândida, mesmo pertencentes a realidades tão díspares, desempenham o mesmo papel. Em The biggest modern woman of the world os filhos mais que perfeitos inexistem. A protagonista sempre gera filhos monstros que não correspondem ao ideal de maternidade normal.

As obras Noites no circo, Exílio e The biggest modern woman of the world criticam e por vezes invertem os modelos tradicionais de família. Nessas narrativas, os conceitos de matrimônio e maternidade são questionados através de mães que não cumprem o seu papel social, de mulheres que cuidam de filhos que não são biologicamente seus, e de casais que subvertem o modelo tradicional de família. Os casamentos presentes nessas narrativas ou não se concretizam ou são insatisfatórios e infelizes. A maternidade para essas protagonistas não corresponde ao padrão normal, no qual a mãe estereotipadamente embala um filho sadio e está amparada sob a proteção de seu marido. A mãe biológica, especialmente nos romances de Carter e Luft, está ausente, e suas filhas se encontram desamparadas em um mundo violento, sem a figura de uma mãe que as proteja.

\begin{abstract}
This paper aims at providing a comparative study of Angela Carter's Nights at the Circus, Lya Luft's Exílio and Susan Swan's The Biggest Modern Woman of the World, focusing on the female grotesque and on views of maternity that deviates from models that are regarded as normal.
\end{abstract}

KEYWORDS

Grotesque, Maternity, Feminism, Alterity

\title{
REFERÊNCIAS
}

BEAUVOIR, Simone de. O segundo sexo: volume 1 - fatos e mitos. 4. ed. Trad. Sérgio Milliet. São Paulo: Difusão Européia do Livro, 1970. 310 p.

BEAUVOIR, Simone de. O segundo sexo: volume 2 - a experiência vivida. 2. ed. Trad. Sérgio Milliet. São Paulo: Difusão Européia do Livro, 1967. 310 p.

CARSON, Fiona. Feminism and the body. In: GAMBLE, Sarah (Ed.). The routledge companion to feminism and postfeminism. London: Routledge, 2001. p. 117-128.

CARTER, Angela. Noites no circo. Trad. Claudia Martinelli Gama. Rio de Janeiro: Rocco, 1991. 336 p. 
CARTER, Angela. The sadeian woman and the ideology of pornography. New York: Pantheon Books, 1978. 154 p.

ECO, Umberto. História da feiúra. Trad. Eliana Aguiar. Rio de Janeiro: Record, 2007. 453 p.

FRIEDAN, Betty. The feminine mystique. New York: W. W. Norton \& Company Ltd., 2001. $587 \mathrm{p}$.

FUNCK, Susana Bornéo. Representações da maternidade e da paternidade na literatura feminista contemporânea. In: SILVA, Alcione Leite da; LAGO, Mara Coelho de Souza; RAMOS, Tânia Regina Oliveira (Org.). Falas de gênero: teorias, análises, leituras. Ilha de Santa Catarina: Editora Mulheres, 1999. p. 301-308.

JOHNSON, Heather. Metafiction, magical realism and myth. In: STODDART, Helen. Angela Carter's Nights at the Circus. London: Routledge, 2007. p. 69-81.

KRISTEVA, Julia. Histórias de amor. Trad. Leda Tenório da Motta. Rio de Janeiro: Paz e Terra, 1988. 423 p.

LUFT, Lya. Exílio. Rio de Janeiro: Record, 2005. 175 p.

LUFT, Lya. Múltipla escolha. Rio de Janeiro: Record, 2010. 189 p.

LUFT, Lya. A riqueza do mundo. Record, 2011. 270 p.

McAFEE, Noëlle. Julia Kristeva: Routledge critical thinkers. New York: Routledge, 2004. $168 \mathrm{p}$.

MILES, Margaret R. Carnal Knowing: Female Nakedness and Religious Meaning in the Christian West. Eugene: Wipf \& Stock Publishers, 2006. 254 p.

NAZÁRIO, Luiz. Da natureza dos monstros. São Paulo: Arte \& Ciência, 1998. 302 p.

RICH, Adrienne Cecile. Of woman born: motherhood as experience and institution. New York: W. W. Norton \& Company Ltd., 1986. 352 p.

RICH, Adrienne Cecile. On lies, secrets and silence: selected prose -1966-1978. London: Virago, 1980. 320 p.

STEVENS, Cristina Maria Teixeira. Maternidade e feminismo: diálogos na literatura contemporânea. In: . Maternidade e feminismo: diálogos interdisciplinares. Santa Cruz do Sul: Editora Mulheres; EDUNISC, 2007. p. 17-73.

SWAN, Susan. Breaking the maternal silence: no more good mothers. In: DRAGU, Margaret; SHEARD, Sarah; SWAN, Susan. Mothers talk back. Toronto: Coach House Press, 1991. p. 207-221.

SWAN, Susan. The biggest modern woman of the world. Toronto: Lester \& Orpen Dennys Limited, 2001. 343 p. 